\title{
Kaposi's Sarcoma in HIV Positive Male
}

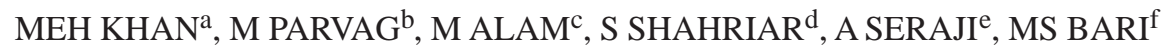

\begin{abstract}
Summary:
Kaposi's sarcoma is a vascular tumor usually involves skin, mucous membrane and other organs. HIV associated Kaposi's sarcoma is very rarely reported in Bangladesh. The reporting case was presented with a recurrent, ulcerated, firm nodule on left groin along with multiple blackish flat or raised lesions on different parts of body. According to previous histopathological report this case
\end{abstract}

\section{Introduction:}

Kaposi's sarcoma is the most common neoplasm of an AIDS patient. ${ }^{1}$ It is a vascular tumor that composed of spindle - shaped cells which express markers for endothelial cells and smooth muscle cells. ${ }^{1,2}$ This rare condition comes to the forefront because of its increased association with HIV infected patient. ${ }^{3}$ In Bangladesh Kaposi's sarcoma has been very rarely reported. We are reporting Kaposi's sarcoma in an HIV positive male of Bangladesh.

a. Dr. Mohammad Emrul Hasan Khan, Assistant Registrar, Burn Plastic \& Reconstructive Surgery Dept. Shaheed Suhrawardi Medical College Hospital.

b. Dr. Masum Parvag, Medical Officer, Plastic \& Reconstructive Surgery Dept. Shaheed Suhrawardi Medical College Hospital

c. Dr. Mahabub Alam, Assistant Registrar, Burn Plastic \& Reconstructive Surgery Dept. Shaheed Suhrawardi Medical College Hospital.

d. Dr. Shaon Shahriar, Assistant Registrar, Burn Plastic \& Reconstructive Surgery Dept. Shaheed Suhrawardi Medical College Hospital.

e. Dr. Ahmad Seraji, Assistant Professor, Burn Plastic \& Reconstructive Surgery Dept. Shaheed Suhrawardi Medical College Hospital

f. Prof. Dr. Md. Shahidul Bari, Professor \& Head of the Dept. Burn Plastic \& Reconstructive Surgery Dept. Shaheed Suhrawardi Medical College Hospital.

Address of Correspondence: Dr. Mohammad Emrul Hasan Khan, Assistant Registrar, Department of Burn, Plastic \& Reconstructive Surgery, Shaheed Suhrawardy Medical College Hospital, Sher - E Bangla Nagar, Dhaka, Bangladesh. Tel.: +8801713242529, E-mail address: dremrul@gmail.com

Received: 25 April, 2013

Accepted: 20 March, 2014 was operated as a case of recurrent fibrous histiocytoma and this time the diagnosis was confirmed histologically and by immunohistochemistry as Kaposi's sarcoma. Later, it was found that the patient is serologically positive for HIV.

Key Words: HIV infection, Kaposi's sarcoma.

(J Banagladesh Coll Phys Surg 2014; 32: 164-166)

\section{Case Report:}

A 28 years old married male presented with a recurrent, dark colored, ulcerated nodule with serous discharge on left groin for about three months which first appeared about four and half months back. At that time the lesion was excised and biopsied locally and histopathology report was fibrous histiocytoma. But the patient presented with local recurrence within one and half month. He also complained of multiple dark colored, flat, raised lesions on different part of body. His first lesion started about five months back on his left arm. Initially all the lesions were small, reddish and macular. With time, lesions were increasing in size and became blackish in color. He worked as a cleaner at Saudi Arab for about five years. There was no history of trauma, fever, significant weight loss or blood transfusion. He did not give any history of sexual exposure.

On examination, there was a firm nodule with ulcerated blackish to pinkish surface about $2 \mathrm{~cm} \times 1.5$ $\mathrm{cm}$ size on left groin. There were multiple ( about 36) plaques on both upper arms, right forearm, front and back of chest, back of trunk, upper part of medial aspect of left thigh, right leg and on hard palate. There was generalized lymphadenopathy. Lymph nodes were discrete, firm and non tender. There was no perianal or intra rectal abnormality. All other general and systemic examinations were normal. Previous histopathology report of this lesion was recurrent fibrous histiocytoma. 


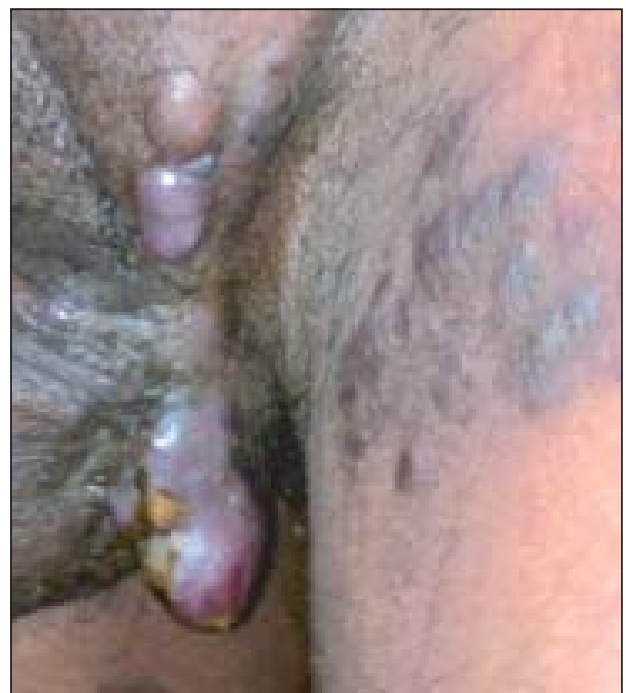

Fig-1: Groin Lesion (Pre operative)

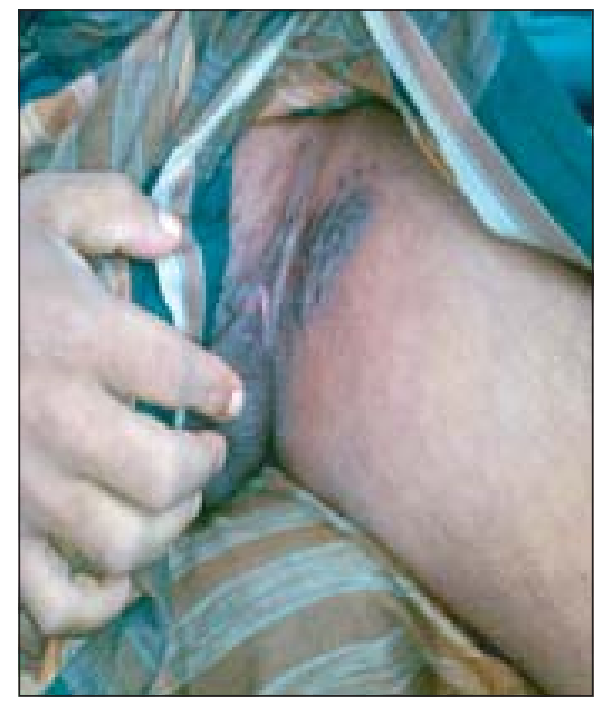

Fig-2: Groin Lesion (Post operative)

His laboratory investigations e.g complete blood count, random blood sugar, serum creatinine, chest $\mathrm{X}$ ray were within normal limit. So that wide local excision of the groin lesion was performed and histopathologically the lesion was diagnosed as Kaposi's sarcoma. To confirm the diagnosis immunohistochemistry was done and report was compatible with Kaposi's sarcoma. FNAC of lymph nodes of cervical and axilarry revealed reactive lymphadenitis. As the tumor is rare but its presence is strongly associated with HIV, so serology for HIV was done and found positive. His CD4 cell count was 90cells/ $\mu$ of blood. On screenings it was found that his wife was also HIV positive but his son was negative.

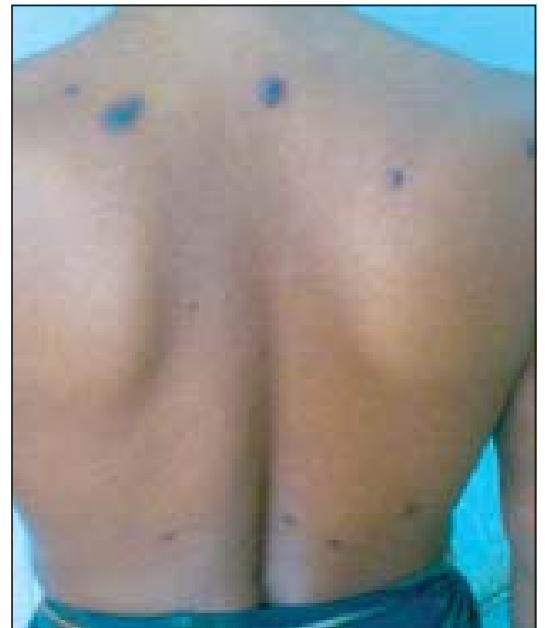

Fig-3: Lesions on Back

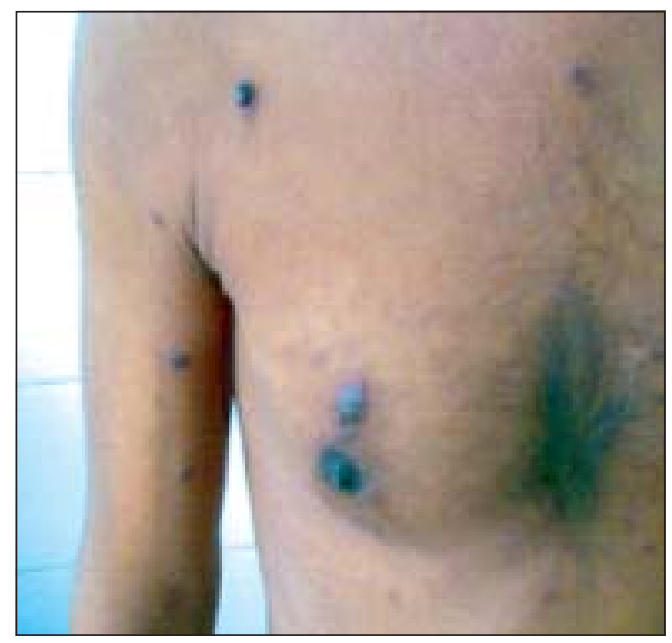

Fig-4: Lesions on Front of chest \& Right Arm

For the better management of AIDS, the patient was referred to Infectious Disease Hospital.

\section{Discussion:}

In 1872 Moriz Kaposi $1^{\text {st }}$ described Kaposi's sarcoma. ${ }^{4,5}$ There are four epidemiological forms of Kaposi's sarcoma - 1) Chronic / classic Kaposi's sarcoma, 2) Lymphadenopathic / endemic Kaposi's sarcoma, 3) Transplant associated Kaposi's sarcoma, 4) HIV related / Epidemic Kaposi's sarcoma. ${ }^{4,5}$ Morpghologically it has 3 stages 1) Patches, 2) Raised Plaques, 3) Nodular. ${ }^{4}$

Kaposi's sarcoma may be seen any time during the course of HIV infection. ${ }^{6}$ The lesions can arise early before the immune system is compromised or in advance 
stage of HIV infection. ${ }^{3}$ In this case there was no other clinical feature of immunosuppression at presentation, but after diagnosis it was found that his CD4 cell count is 90 cells $/ \mu \mathrm{l}$ of blood which indicates immunosupression.

The presentation and natural course of Kaposi's sarcoma vary widely. ${ }^{4,6}$ HIV associated Kaposi's sarcoma has no site predilection in comparison to the classic variety, where lesions are common on the lower extremities. 3,5,6 Patient with HIV associated Kaposi's sarcoma usually present with skin lesion on upper half of body but some patient may present with gastrointestinal tract or lymphnode involvement. ${ }^{5,6,7}$ This presenting case has about 35 skin lesions mostly on upper half of body.

HIV associated Kaposi's sarcoma can affect the skin, GIT, lymph node and lung. ${ }^{7}$ But usual causes of death in HIV associated Kaposi's sarcoma are opportunistic infection and systemic involvement of HIV especially of the pulmonary system. $., 5,7,8$

In 1994 Human Herpes Virus-8 (Kaposi's sarcoma associated Herpes Virus - KSHV) was identified in cutaneous Kaposi's sarcoma. ${ }^{4,9}$ It is transmitted sexually and Kaposi's sarcoma is more common among homosexual or bisexual HIV patient. ${ }^{4,7,8}$ But recent publication also reported its occurrence in heterosexual male. ${ }^{7,10}$ The reported case is an HIV positive heterosexual male.

Kaposi's sarcoma in an HIV infected patient is the indication to start antiretroviral therapy. ${ }^{6}$ HAART forms the mainstay of treatment which has significantly changed the morbidity and mortality associated with Kaposi's sarcoma. ${ }^{7}$ In case of few skin lesions with no systemic involvement local treatment like wide excision, radiotherapy or intra-lesional chemotherapy may be used. ${ }^{6,11}$ But in case of visceral involvement or extensive Kaposi's sarcoma HAART along with doxorubicin or Paclitaxel can be used as systemic therapy or immunotherapy with interleukin 2 or interferon may use. $^{6,7,11}$

Chance of becoming infected with HIV at operation of HIV patient has been assumed about 1 in 130000 cases. ${ }^{11}$ So to prevent transmission, preoperative screening has been advocated, but in the context of our country pre operative screening in all patients is not practically possible or feasible, if not he had some features to assume as HIV positive patient. As an alternative it is better to practice a policy of universal precaution, such as at least safer handling of sharp \& pointed instruments and double gloving.

In this reporting case, patient did not show the typical profile of an HIV infected patient and so that pre operative screening for HIV was not done. After the post operative histopathological study, clinical diagnosis of HIV infection came in front.

\section{Conclusion:}

The surgical team operated on this patient was under greater risk of transmission of HIV. So we encourage for the adaption of a high standard of precaution measures in all patients. BCPS started basic surgical skill training where universal precaution and safe sharp instrument handling are important parts. But that should be trained to all doctors and all staffs working in the operation theatres.

\section{References:}

1. Kumar V, Abbas AK, Fausto N, Aster JC. Pathologic Basis of Disease 2011( $\left.8^{\text {th }}\right) ; 6$ : 246-7.

2. Tahir JM, Gopalan KN, Marina MB, Putra SHAP. A rare case of laryngeal Kaposi's sarcoma. Bangladesh Journal of Medical Science2010; 9(2):107-9.

3. Schoen FJ, Cortan RS. Blood vessels. Pathologic Basis of Disease 1999(6 $\left.6^{\text {th }}\right)$; 12: 493-543.

4. Schoen FJ, Mitchel RN. Blood vessels. Pathologic Basis of Disease 2011( $\left.8^{\text {th }}\right)$; 12: 487-528.

5. Modlin RL, Crissey JT, Rea TH. Kaposi's sarcoma. International Journal of Dermatology 1983; 22:443-8.

6. Dongre A, Montaldo C. Kaposi's Sarcoma in an HIV positive person successfully treated with paclitaxel. Indian J Dermatol Venereol Leprol 2009; 75(3): 290-2.

7. Kharkar V, Gutte RM, Khopkar U, Mahajan S, Chikhalkar S. Kaposi's Sarcoma: A presenting manifestation of HIV infection in an Indian. Indian J Dermatol Venereol Leprol 2009; 75(4): 391-3.

8. Hernandez DE, Perez JR, Wilder J, Muci R. Kaposi's sarcoma associated with human immunodeficiency virus infection. International Journal of Dermatology 1991; 30(2): 109-113.

9. Serwin AB, Mysliwiec H, Wilder N, Schwartz RA, Chodynicka B. Three cases of classic Kaposi's sarcoma with different subtypes of Kaposi's sarcoma - associated herpesvirus. International Journal of Dermatology 2006; 45: 843-6.

10. Chandan k, Madnani N, Desai D, Deshpande R. AIDS associated Kaposi's sarcoma in a heterosexual male. Dermatology Online Journal2002; 8(2): 19.

11. Mertinez RG, Bertolin SM, Escribano JM, Velayos JA. Nodular Kaposi's sarcoma as a presenting feature of HIV infection. International Journal of Dermatology 1996; 35(11): 813-5. 